\title{
Preparation of Cobalt Nanocrystals Supported on Metal Oxides To Study Particle Growth in Fischer-Tropsch Catalysts
}

\author{
Tom W. van Deelen, ${ }^{\circledR}$ Jelle J. Nijhuis, Nynke A. Krans, Jovana Zečević, and Krijn P. de Jong*
}

Inorganic Chemistry and Catalysis, Debye Institute for Nanomaterials Science, Utrecht University, Universiteitsweg 99,3584 CG Utrecht, The Netherlands

\section{Supporting Information}

ABSTRACT: Colloidal synthesis of nanocrystals (NC) followed by their attachment to a support and activation is a promising route to prepare model catalysts for research on structureperformance relationships. Here, we investigated the suitability of this method to prepare well-defined $\mathrm{Co} / \mathrm{TiO}_{2}$ and $\mathrm{Co} / \mathrm{SiO}_{2}$ catalysts for the Fischer-Tropsch (FT) synthesis with high control over the cobalt particle size. To this end, Co-NC of 3, 6, 9, and $12 \mathrm{~nm}$ with narrow size distributions were synthesized and attached uniformly on either $\mathrm{TiO}_{2}$ or $\mathrm{SiO}_{2}$ supports with comparable morphology and Co loadings of 2-10 wt \%. After activation in $\mathrm{H}_{2}$, the FT activity of the $\mathrm{TiO}_{2}$-supported 6 and 12 $\mathrm{nm}$ Co-NC was similar to that of $\mathrm{a} \mathrm{Co} / \mathrm{TiO}_{2}$ catalyst prepared by impregnation, showing that full activation was achieved and relevant catalysts had been obtained; however, $3 \mathrm{~nm}$ Co-NC on $\mathrm{TiO}_{2}$ were less active than anticipated. Analysis after FT revealed that all Co-NC on $\mathrm{TiO}_{2}$ as well as $3 \mathrm{~nm} \mathrm{Co-NC}$ on $\mathrm{SiO}_{2}$ had grown to $\sim 13 \mathrm{~nm}$, while the sizes of the 6 and $9 \mathrm{~nm}$ Co$\mathrm{NC}$ on $\mathrm{SiO}_{2}$ had remained stable. It was found that the $3 \mathrm{~nm} \mathrm{Co}-\mathrm{NC}$ on $\mathrm{TiO}_{2}$ already grew to $10 \mathrm{~nm}$ during activation in $\mathrm{H}_{2}$. Furthermore, substantial amounts of $\mathrm{Co}$ (up to 60\%) migrated from the Co-NC to the support during activation on $\mathrm{TiO}_{2}$ against only $15 \%$ on $\mathrm{SiO}_{2}$. We showed that the stronger interaction between cobalt and $\mathrm{TiO}_{2}$ leads to enhanced catalyst restructuring as compared to $\mathrm{SiO}_{2}$. These findings demonstrate the potential of the NC-based method to produce relevant model catalysts to investigate phenomena that could not be studied using conventionally synthesized catalysts.

KEYWORDS: colloidal synthesis, cobalt nanocrystals, supported catalysts, Fischer-Tropsch synthesis, particle growth, metal-support interaction

\section{INTRODUCTION}

Metal nanoparticles on a support material are widely applied as heterogeneous catalysts in industrial processes. ${ }^{1-4}$ In order to improve industrial catalyst design, it is a prerequisite to link their structure to their performance which requires welldefined model catalysts. ${ }^{5,6}$ Several nanotechnological techniques have recently been developed that allow the synthesis of catalysts with high control over parameters such as composition, size, or shape of metal nanoparticles. ${ }^{5,7}$

Among the available techniques, the colloidal synthesis of nanocrystals (NC) is especially promising for the preparation of catalysts. By preforming the NC in solution instead of directly on the support as is custom in conventional synthesis techniques, it is possible to synthesize monodisperse, single crystalline, and size-controlled NC. ${ }^{8}$ The vast majority of the research so far focused on noble metal NC even though base metals are very important for catalysis. However, base metal $\mathrm{NC}$ are more challenging to utilize in supported catalysts. First, homogeneous attachment of base metal NC on a support can be hindered by magnetic interactions between the $\mathrm{NC}$. Second, removal of the stabilizing ligand shell can be incomplete, blocking active sites and lowering catalytic activity, or harsh treatments are applied that may compromise the welldefined nature of the catalyst. ${ }^{10,11}$ Recently we demonstrated uniform attachment and successful ligand removal for Co-NC supported on carbon nanotubes by applying a mild, lowtemperature oxidation to the $\mathrm{NC}$ in suspension prior to attachment. $^{12}$

A particular application where NC-based catalysts can contribute to fundamental understanding is the FischerTropsch (FT) synthesis, i.e. the catalytic conversion of synthesis gas (an $\mathrm{H}_{2} / \mathrm{CO}$ mixture) into hydrocarbon fuels and chemicals. ${ }^{13}$ The cobalt-catalyzed FT reaction is reported to be structure sensitive, related to both cobalt particle size $\mathrm{e}^{14,15}$ and cobalt crystal structure. ${ }^{16-18}$ So far, most research involving Co-NC for FT concentrated either on slurry-phase $\mathrm{FT}$, in which the unsupported Co-NC remain in suspension, ${ }^{19-21}$ or on Co-NC supported on irreducible oxides (mainly $\mathrm{SiO}_{2}$ or $\mathrm{Al}_{2} \mathrm{O}_{3}$ ). ${ }^{22-29}$ However, reducible oxides such

Received: August 3, 2018

Revised: September 25, 2018

Published: October 5, 2018 
as $\mathrm{TiO}_{2}$ are also interesting supports for cobalt-based FT catalysts, for both industry ${ }^{30}$ and academia. ${ }^{31}$

$\mathrm{TiO}_{2}$-supported cobalt catalysts can be considered more complex than $\mathrm{Co} / \mathrm{SiO}_{2}$ or $\mathrm{Co} / \mathrm{Al}_{2} \mathrm{O}_{3}$, since $\mathrm{TiO}_{2}$ can be partially reduced under reaction conditions, leading to special interphase phenomena known as strong metal-support interactions (SMSI). ${ }^{32,33}$ The effects of these metal- $\mathrm{TiO}_{2}$ interactions remain poorly understood, in part because synthesis procedures for well-defined catalysts are lacking, especially for $<10 \mathrm{~nm}$ Co particles. $\mathrm{TiO}_{2}$-supported catalysts with narrow Co particle size distributions can be synthesized using conventional methods, but the control over the average particle size is limited. ${ }^{34,35}$ Furthermore, there are only a few reports of $\mathrm{NC}$-based $\mathrm{Co} / \mathrm{TiO}_{2}$ catalysts, and these either contained boron impurities owing to the synthesis method ${ }^{36,37}$ or the Co-NC were $10 \mathrm{~nm}$ or larger. ${ }^{24,38}$ Therefore, it would be highly desirable to expand the applicability of $\mathrm{Co}-\mathrm{NC}$ to $\mathrm{TiO}_{2}$ as support.

Here we report the synthesis and catalytic performance of well-defined catalysts containing 3-12 nm Co-NC on $\mathrm{TiO}_{2}$ and $\mathrm{SiO}_{2}$ and demonstrate their use as model systems by studying particle growth under FT conditions. The Co-NC were synthesized by a hot-injection method. After lowtemperature oxidation, the $\mathrm{CoO}-\mathrm{NC}$ were homogeneously attached to either $\mathrm{TiO}_{2}$ or $\mathrm{SiO}_{2}$. Their catalytic performance was comparable to that of $\mathrm{Co} / \mathrm{TiO}_{2}$ prepared by impregnation, except for $3 \mathrm{~nm}$ Co-NC on $\mathrm{TiO}_{2}$, whose activity was substantially lower. The $\mathrm{TiO}_{2}$-supported $\mathrm{Co}$ particles and 3 $\mathrm{nm}$ Co-NC on $\mathrm{SiO}_{2}$ sintered during reduction and/or FT, indicating that both the support and initial NC size affected the stability of Co-NC under reaction conditions. We show that the followed NC-based methodology enabled the synthesis of size-controlled $\mathrm{Co} / \mathrm{TiO}_{2}$ and $\mathrm{Co} / \mathrm{SiO}_{2}$ with relevant catalytic performance. Their potential as model systems is underlined by investigating $\mathrm{NC}$ particle growth, revealing phenomena that are not observed with conventionally prepared catalysts.

\section{EXPERIMENTAL METHODS}

Cobalt Nanocrystal Synthesis. Cobalt nanocrystals of different sizes were synthesized by a hot injection method based on the literature ${ }^{39}$ and our previous work. ${ }^{12}$ A schematic summary of the NC synthesis procedure is shown in Figure S1. The benefit of this method is that the required chemicals contain no elements such as phosphorus or boron that might affect the catalyst and its final catalytic performance. The syntheses were performed on a Schlenk line in $\mathrm{N}_{2}$ atmosphere. In a typical synthesis, $65 \mathrm{mg}$ of oleic acid (Sigma-Aldrich, 90\%, technical grade) was degassed under vacuum at $100{ }^{\circ} \mathrm{C}$ for 30 min in a 3-necked $100 \mathrm{~mL}$ flask with a cooler and two septa. After flushing and switching to $\mathrm{N}_{2}, 7.5 \mathrm{~mL}$ of 1,2dichlorobenzene was added under inert atmosphere, and the solution was heated to temperatures between 165 and $182{ }^{\circ} \mathrm{C}$ related to the desired NC size. Simultaneously, inside a glovebox, $270 \mathrm{mg}$ of dicobalt octacarbonyl (Acros Organics, $95 \%$, stabilized) was dissolved in $1.5 \mathrm{~mL}$ of 1,2 -dichlorobenze. This cobalt precursor was then rapidly injected (needle: $\varnothing 0.9$ $\times 70 \mathrm{~mm}$ ) into the heated solution under $750 \mathrm{rpm}$ magnetic stirring and decomposed instantly. The reaction was quenched after 20 min using a water bath. Once at ambient temperature, the $\mathrm{N}_{2}$ supply was switched off, and one septum was removed to allow low-temperature oxidation by air-exposure under 650 rpm stirring. After $1 \mathrm{~h}$, the mixture was divided over two glass centrifuge tubes, filled to $20 \mathrm{~mL}$ with 2-propanol (Sigma-
Aldrich, >99\%, LC-MS Chromasolv), and centrifuged at 2200 $\mathrm{G}$ for $30 \mathrm{~min}$. The supernatant was decanted, and the residue was redispersed in $0.5 \mathrm{~mL}$ of $n$-hexane (Acros Organics, 99+ $\%)$ per tube by sonication. The tubes were filled to $20 \mathrm{~mL}$ with 2-propanol and centrifuged at $2200 \mathrm{G}$ for $40 \mathrm{~min}$. This washing cycle was repeated twice, and after the last step, the residue was redispersed and combined in a total of $2 \mathrm{~mL}$ of $n$ hexane.

Cobalt Nanocrystal Attachment. The Co-NC were attached to a support according to the method developed by Casavola et al. ${ }^{40}$ A schematic summary of the NC attachment procedure is shown in Figure $\mathrm{S} 1$. The supports were $\mathrm{TiO}_{2}$ (Evonik, Aeroxide P25) or $\mathrm{SiO}_{2}$ (Evonik, Aerosil OX 50), both sieved to a fraction of $75-150 \mu \mathrm{m}$. To regulate the final cobalt loading, between 0.4 and $2.5 \mathrm{~g}$ of support was suspended in a mixture of the colloidal suspension and 5-31 mL of 1octadecene (Sigma-Aldrich, 90\%, technical grade) inside a 100 $\mathrm{mL}$ 3-necked flask. A cooler, glass plug, and septum were connected to the flask, the magnetic stirring was set to 400 $\mathrm{rpm}$, and the suspension was degassed under vacuum at 100 ${ }^{\circ} \mathrm{C}$ for $15 \mathrm{~min}$, during which the $n$-hexane from the colloidal suspension evaporated. The setup was then flushed, switched to $\mathrm{N}_{2}$, and heated to $200{ }^{\circ} \mathrm{C}$. The heating was stopped after 30 min at $200{ }^{\circ} \mathrm{C}$, and the solution was cooled to ambient temperature in approximately $30 \mathrm{~min}$. The suspension was divided over two glass centrifuge tubes and centrifuged at 1500 $\mathrm{G}$ for $5 \mathrm{~min}$, and the supernatant was decanted. The residue was resuspended in $2 \mathrm{~mL}$ of $n$-hexane, sonicated for $1 \mathrm{~min}$, diluted with $6 \mathrm{~mL}$ of acetone, and centrifuged at $1500 \mathrm{G}$ for 5 min, and the supernatant was again decanted. This washing cycle was repeated five times, followed by resuspending the residue in $20 \mathrm{~mL}$ of acetone, sonicating for $1 \mathrm{~min}$, centrifuging at $1500 \mathrm{G}$ for $5 \mathrm{~min}$, and decanting the supernatant. Afterward, the samples were dried at $60{ }^{\circ} \mathrm{C}$ for $1 \mathrm{~h}$ in static air, followed by $120^{\circ} \mathrm{C}$ for $3 \mathrm{~h}$ in static air and $80{ }^{\circ} \mathrm{C}$ for $3 \mathrm{~h}$ under vacuum. Finally, the samples were sieved to a grain size of 75-150 $\mu \mathrm{m}$.

Incipient Wetness Impregnation. A comparison Co/ $\mathrm{TiO}_{2}$ sample was prepared by incipient wetness impregnation following the procedure by Eschemann et al. ${ }^{34}$ First, $2 \mathrm{~g}$ of $\mathrm{TiO}_{2}$ (Evonik, Aeroxide P25) was sieved to $75-150 \mu \mathrm{m}$ and then dried at $80{ }^{\circ} \mathrm{C}$ for $1 \mathrm{~h}$ under vacuum. The vacuum was released and the $\mathrm{TiO}_{2}$ was impregnated directly afterward with a pore-filling amount of precursor solution consisting of $\mathrm{Co}\left(\mathrm{NO}_{3}\right)_{2} \cdot 6 \mathrm{H}_{2} \mathrm{O}$ (Acros Organics, 99+ \%) in Milli-Q water. The solution was added dropwise under magnetic and manual stirring. After the addition, the powder was dried and heat treated in a U-shaped, glass reactor in fluidized bed mode $(1 \mathrm{~L}$. $\mathrm{min}^{-1}$ upward flow of $\mathrm{N}_{2}$ ). Drying took place at $80^{\circ} \mathrm{C}$ for $2 \mathrm{~h}$ and was followed directly by a thermal treatment at $250{ }^{\circ} \mathrm{C}$ for $2 \mathrm{~h}$, both with $2{ }^{\circ} \mathrm{C} \cdot \mathrm{min}^{-1}$. The sample was finally sieved again to a grain size of $75-150 \mu \mathrm{m}$.

Plasma Cleaning. Optionally, pristine Co-NC samples were plasma cleaned to remove the ligands prior to reduction and FT. Typically, $100 \mathrm{mg}$ of sample was treated for $8 \mathrm{~h}$ in a homemade container inserted into a Fischione Model 1020 Plasma Cleaner. The plasma was generated using a $25 \% \mathrm{O}_{2}$ in Ar flow and a $13.56 \mathrm{MHz}$ oscillating electromagnetic field.

Characterization. Transmission electron microscopy (TEM) was performed either on a Tecnai 12 (FEI), operated at $120 \mathrm{kV}$, or on a Tecnai 20 (FEI), operated at $200 \mathrm{kV}$. TEM samples of Co-NC suspensions were prepared by sonicating and dropcasting a diluted sample directly on a carbon-coated TEM grid. To prepare a sample of supported Co-NC, the solid 
was first suspended in 2-propanol by sonication and then dropcasted on a TEM grid. In the case of samples after catalysis, the samples were washed three times using toluene and 30 min sonication and once using $n$-hexane to remove the hydrocarbon reaction products before dropcasting on a TEM grid. The sizes of $>200$ Co particles were determined manually using ImageJ software. All particle sizes are reported as the Sauter mean diameter (volume/surface mean, $\mathrm{D}[3,2]$ ) of the equivalent metallic cobalt particles, meaning that the measured diameters of (partial) cobalt oxide particles were corrected based on the densities of the oxide and the metal.

Scanning transmission electron microscopy combined with energy-dispersive X-ray spectroscopy (STEM-EDX) was performed in high-angle annular dark-field (HAADF) mode on a Talos F200X (FEI), equipped with a high-brightness field emission gun (X-FEG) and a Super-X G2 EDX detector and operated at $200 \mathrm{kV}$. Particle size analysis was similar to that of TEM, with the exception that $<200$ particles were analyzed for some samples, depending on the particle size and cobalt loading.

HAADF-STEM-EDX of the same positions of $12 \mathrm{~nm}$ Co$\mathrm{NC}$ on $\mathrm{TiO}_{2}$ before and after reduction was performed using a SiN TEM chip (TEMWindow SN100-A50Q33). After imaging the pristine sample, the SiN TEM chip was transferred to a glass U-shaped reactor, and the sample on the chip was reduced ex situ in $25 \% \mathrm{H}_{2}$ in Ar flow at $350{ }^{\circ} \mathrm{C}$ for $8 \mathrm{~h}$ with 1 ${ }^{\circ} \mathrm{C} \cdot \mathrm{min}^{-1}$ and cooled down afterward under the same atmosphere. Subsequently, the chip was transferred back to the microscope and analyzed again. During the transfer, the sample was exposed to air at ambient conditions.

$\mathrm{N}_{2}$-physisorption of the bare supports was measured at $-196{ }^{\circ} \mathrm{C}$ on a Tristar 3000 (Micromeritics). The samples were dried in $\mathrm{N}_{2}$ at $300{ }^{\circ} \mathrm{C}$ for $14-20 \mathrm{~h}$ prior to the analysis.

Inductively coupled plasma-optical emission spectroscopy (ICP-OES) was carried out on a SPECTRO ARCOS, and the sample was digested in aqua regia to extract the cobalt.

Temperature programed reduction (TPR) profiles were measured on an Autochem 2920 (Micromeritics). Approximately $100 \mathrm{mg}$ of sample was reduced in $5 \% \mathrm{H}_{2}$ in Ar flow from 50 to $800{ }^{\circ} \mathrm{C}$ with $5{ }^{\circ} \mathrm{C} \cdot \mathrm{min}^{-1}$.

$\mathrm{X}$-ray diffraction (XRD) was performed on a Bruker D2 Phaser, equipped with a Co radiation source $(\lambda=1.789 \AA)$. The sample was measured between 20 and $100^{\circ} 2 \theta$ with an increment of $0.05^{\circ}$.

Fischer-Tropsch Synthesis. The catalytic performance in the Fischer-Tropsch synthesis was investigated using an Avantium Flowrence 16 parallel reactor setup. Stainless steel plug flow reactors of 2.0 or $2.6 \mathrm{~mm}$ ID were loaded with 25$110 \mathrm{mg}$ of catalyst $(75-150 \mu \mathrm{m})$ diluted with $100 \mathrm{mg}$ of $\mathrm{SiC}$ $(200-425 \mu \mathrm{m})$. Prior to reaction, the catalysts were reduced in situ at 1 bar in $25 \% \mathrm{H}_{2}$ in $\mathrm{He}$ flow at either $350{ }^{\circ} \mathrm{C}\left(\mathrm{TiO}_{2}-\right.$ samples) or $500{ }^{\circ} \mathrm{C}\left(\mathrm{SiO}_{2}\right.$-samples $)$ for $8 \mathrm{~h}$ with $1{ }^{\circ} \mathrm{C} \cdot \mathrm{min}^{-1}$. Afterward, the reactors were cooled to $180{ }^{\circ} \mathrm{C}$ and pressurized to 20 bar. At these conditions, the atmosphere was switched to synthesis gas with $\mathrm{H}_{2} / \mathrm{CO}=2(\mathrm{v} / \mathrm{v})$ and $5 \% \mathrm{He}$ as internal standard. Subsequently, the reactors were heated to $220{ }^{\circ} \mathrm{C}$ with $1{ }^{\circ} \mathrm{C} \cdot \mathrm{min}^{-1}$, and product analysis was started after $1 \mathrm{~h}$. The reaction products were analyzed online using an Agilent 7890A GC equipped with two channels. The first channel contained an Agilent J\&W PoraBOND Q column connected to an FID to detect the hydrocarbon products, and the second one consisted of a ShinCarbon-ST column connected to a $\mathrm{TCD}$ to analyze the permanent gases.
The catalytic activity was reported as $\mathrm{CO}$ conversion $\left(X_{\mathrm{CO}}\right)$, cobalt time yield (CTY), and turnover frequency (TOF). The TOF was based on the activity and the Sauter mean diameter $(\mathrm{D}[3,2])$ of the spent Co-NC after correction for a $3 \mathrm{~nm} \mathrm{CoO}$ passivation layer, assuming a cross-sectional area of $0.0662 \mathrm{~nm}^{2}$ per cobalt atom. ${ }^{41}$ The selectivity $\left(\%_{\mathrm{C}}\right)$ to $\mathrm{C}_{1}-\mathrm{C}_{4}$ products was defined as $S_{\mathrm{C} 1-\mathrm{C} 4}=100 \% \cdot F_{\mathrm{Cn}} \cdot n \cdot\left(F_{\mathrm{CO}, \text { in }} \cdot X_{\mathrm{CO}}\right)^{-1}$ with $n$ being the product's carbon number and $F$ being the flow of the corresponding hydrocarbon or $\mathrm{CO}$. The selectivity to $\mathrm{C}_{5+}$ was defined as $S_{\mathrm{C} 5+}=100 \%-S_{\mathrm{C} 1-\mathrm{C} 4}$.

\section{RESULTS AND DISCUSSION}

Cobalt Nanocrystal Synthesis. Well-defined cobalt nanocrystals were synthesized with distinct sizes between 3 and $12 \mathrm{~nm}$ and a polydispersity of $11-18 \%$ (Figure 1,
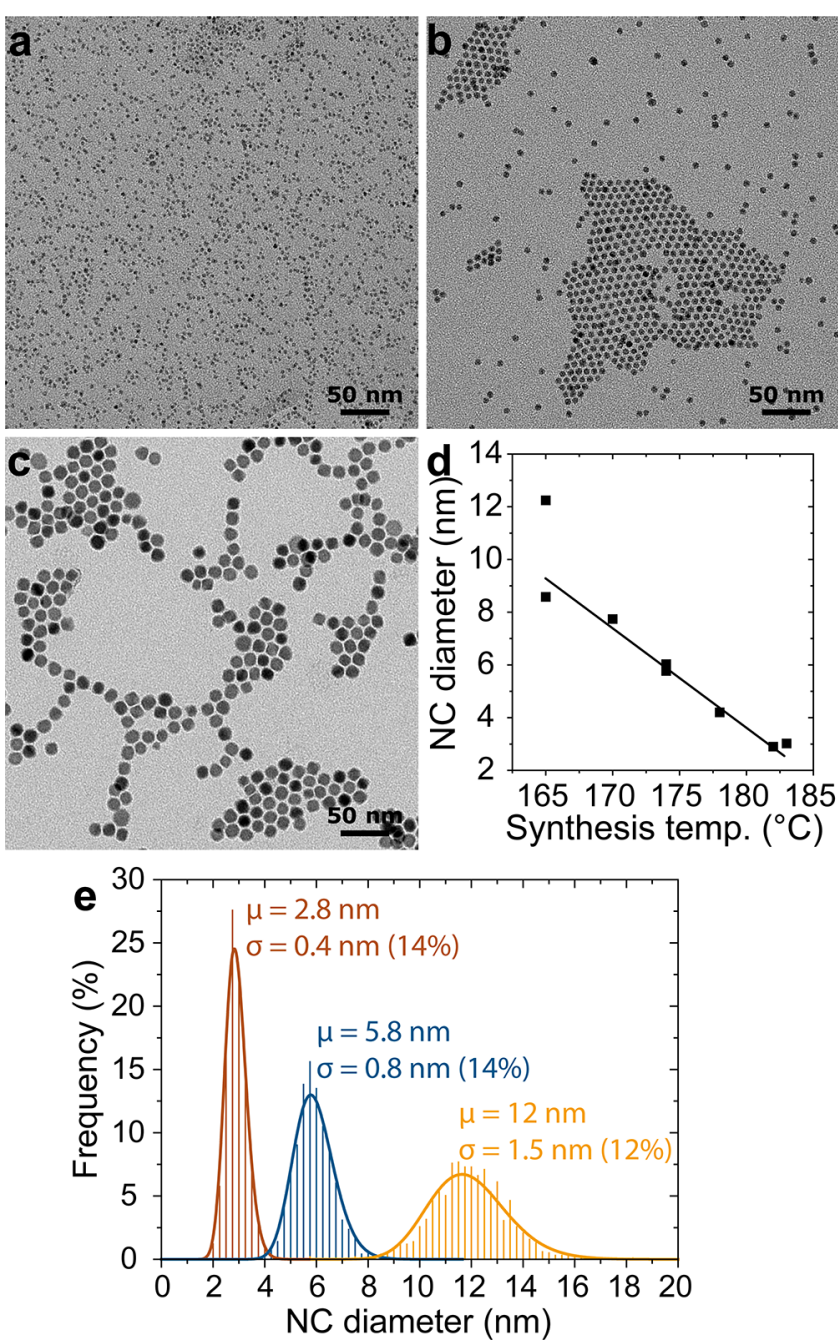

Figure 1. Overview of the as-synthesized Co-NC. TEM images of (a) Co3, (b) Co6, and (c) Co12 and (d) the resulting Co-NC size as a function of the hot-injection temperature. (e) Histograms and the lognormal distributions of selected sizes of Co-NC.

additional particle size distributions in Figure S2). The Co-NC were designated as $\mathrm{CoX}$, with $\mathrm{X}$ denoting the average diameter of the NC. The size of the Co-NC size was regulated by varying the temperature of the hot injection synthesis, which is in line with the literature. ${ }^{39,42}$ The Co-NC size correlated with the synthesis temperature in the range of $170-183{ }^{\circ} \mathrm{C}$ and 
became less reproducible at lower temperature (Figure 1d). After the synthesis, low-temperature oxidation by air-exposure at ambient conditions was applied to facilitate attachment and activation of the Co-NC. ${ }^{12}$ The Co-NC of $3,6,9$, and $12 \mathrm{~nm}$ were attached to $\mathrm{TiO}_{2}$ or $\mathrm{SiO}_{2}$, thus omitting the Co-NC of 4 and $8 \mathrm{~nm}$ in Figure 1d.

Cobalt Nanocrystal Attachment. The Co-NC were attached to titania and silica with comparable specific surface areas $\left(\sim 50 \mathrm{~m}^{2} \cdot \mathrm{g}^{-1}\right)$ but different mesopore volumes $(0.3$ and $0.1 \mathrm{~mL} \cdot \mathrm{g}^{-1}$, respectively) as determined by $\mathrm{N}_{2}$-physisorption (Figure S3, Table S1). The cobalt loading was adjusted to obtain similar cobalt metal surface areas per unit weight of catalyst in the pristine samples with the aim to avoid major differences in catalyst-weight-based activities during FT (Table 1). Furthermore, the Co-NC on the supports were analyzed

Table 1. Characteristics of the Supported Co-NC and IWICo Samples ${ }^{a}$

$\begin{array}{cccc}\text { sample } & \begin{array}{c}\mathrm{D}[3,2]_{\mathrm{Co}-\mathrm{NC}} \\ (\mathrm{nm})\end{array} & \begin{array}{c}\text { Co loading } \\ (\text { wt } \%)\end{array} & \begin{array}{c}\text { initial Co surface area } \\ \left(\mathrm{m}_{\mathrm{Co}}{ }^{2} \cdot \mathrm{g}_{\mathrm{Cat}}{ }^{-1}\right)\end{array} \\ \mathrm{Co} 3 / \mathrm{TiO}_{2} & 2.9 \pm 0.4 & 2.4 & 5.7 \\ \mathrm{Co} 6 / \mathrm{TiO}_{2} & 6.0 \pm 0.8 & 4.6 & 5.5 \\ \mathrm{Co} 12 / \mathrm{TiO}_{2} & 12 \pm 1.5 & 8.7 & 5.4 \\ \mathrm{IWI}-\mathrm{Co} / & 7.3 \pm 2.5 & 6.7 & 6.2 \\ \mathrm{TiO}_{2} & & & \\ \mathrm{Co} 3 / \mathrm{SiO}_{2} & 2.8 \pm 0.5 & 3.6 & 6.8 \\ \mathrm{Co} 6 / \mathrm{SiO}_{2} & 5.6 \pm 0.6 & 6.8 & 9.2 \\ \mathrm{Co} 9 / \mathrm{SiO}_{2} & 8.6 \pm 1.1 & 9.6 & 7.7\end{array}$

${ }^{a}$ The Sauter mean diameter ( \pm standard deviation) of the Co-NC was analyzed by TEM before attachment and recalculated to the corresponding $\mathrm{Co}^{0}$ particle sizes. The Co loading was determined by ICP-OES. Based on these two results, a Co specific surface area of the pristine catalysts was calculated.

with TEM (Figure 2). The Co-NC distribution was uniform over both supports, similar to previous results with a carbon support. $^{12,40}$ In addition, a reference $\mathrm{Co} / \mathrm{TiO}_{2}$ sample was prepared by conventional techniques, in this case incipient wetness impregnation of a cobalt nitrate solution (designated as IWI-Co/TiO 2 , details in Table 1 and TEM results in Figure S4). Its average particle size was most comparable to Co6/ $\mathrm{TiO}_{2}$, but the particle size distribution was substantially broader.

The sizes of the Co-NC remained unchanged during the attachment treatment as concluded from TEM (Figure 2). The Co-NC of 3 and $6 \mathrm{~nm}$ consisted completely of $\mathrm{CoO},{ }^{12}$ while for the 9 and $12 \mathrm{~nm}$ Co-NC only an outer layer of $\mathrm{CoO}$ was formed and a metallic core with higher contrast was observed. This CoO shell had a thickness of $4.5 \mathrm{~nm}$ in the case of Co12/ $\mathrm{TiO}_{2}$, which exceeds the $\mathrm{CoO}$ passivation layer of $3 \mathrm{~nm}$ that is typically observed upon exposure of metallic cobalt particles to air at ambient conditions. ${ }^{43}$ The increased oxidation of the CoNCs could have occurred during drying at $120^{\circ} \mathrm{C}$, as this is close to the temperature range where Kirkendall effects have been observed. ${ }^{44}$ The Kirkendall effect occurs upon oxidation of metals at elevated temperatures and leads to the formation of hollow metal oxide particles. ${ }^{11,45}$

The reducibility of the Co-NC on $\mathrm{TiO}_{2}$ samples was investigated by temperature-programmed reduction (TPR, Figure $3 \mathrm{a}$ ). Two reduction peaks were observed between 250 and $450{ }^{\circ} \mathrm{C}$ for all samples next to a negative peak at higher temperatures, which is attributed to the desorption/decomposition of remaining ligands. ${ }^{12}$ As expected, the reduction
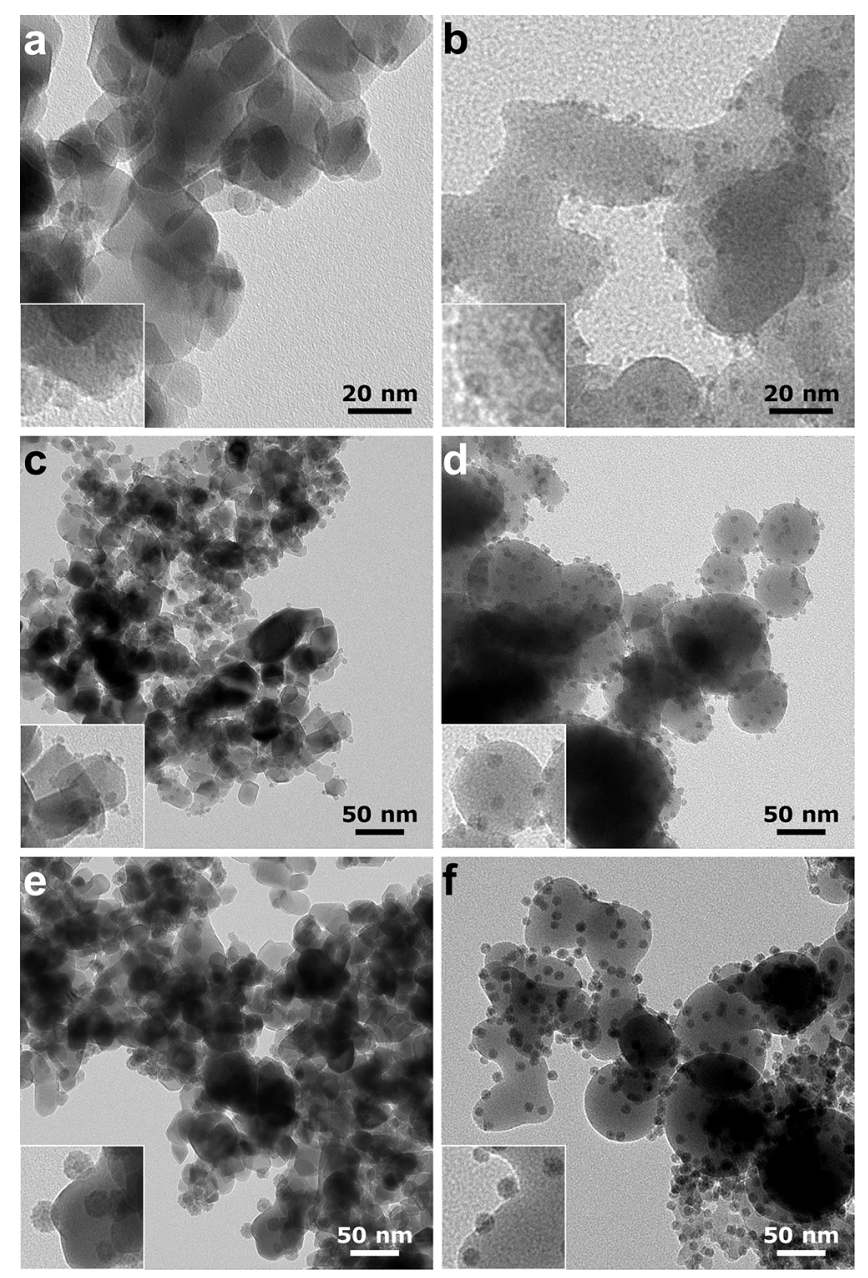

Figure 2. Overview of the Co-NC attached to a support. The $\mathrm{TiO}_{2-}$ supported samples are in the left column, and the $\mathrm{SiO}_{2}$-supported samples are in the right column. (a) $\mathrm{Co} 3 / \mathrm{TiO}_{2}$, (b) $\mathrm{Co} 3 / \mathrm{SiO}_{2}$, (c) $\mathrm{Co} 6 / \mathrm{TiO}_{2}$, (d) $\mathrm{Co} 6 / \mathrm{SiO}_{2}$, (e) $\mathrm{Co} 12 / \mathrm{TiO}_{2}$, and (f) $\mathrm{Co} 9 / \mathrm{SiO}_{2}$. The insets are at double the magnification of the original image.

shifted to lower temperatures with increasing particle size, because small oxide particles often display lower reducibility. ${ }^{46-48}$ Furthermore, the total $\mathrm{H}_{2}$-uptake related to the first two peaks increased with the particle size following the increase in cobalt content. When comparing the total $\mathrm{H}_{2}$ uptake of the Co-NC/ $\mathrm{TiO}_{2}$ samples normalized to the amount of $\mathrm{Co}$, the $\mathrm{H}_{2}$-uptake of $\mathrm{Co} 12 / \mathrm{TiO}_{2}$ was only $89-92 \%$ of that of the 3 and $6 \mathrm{~nm} \mathrm{NC} \mathrm{(deconvolutions} \mathrm{in} \mathrm{Figure} \mathrm{S5).} \mathrm{This}$ indicated that $\sim 10 \%$ of the cobalt in $\mathrm{Co} 12 / \mathrm{TiO}_{2}$ was still present in the core of the NC as metallic cobalt, which was in line with the earlier TEM observation of a metallic core and a $\mathrm{CoO}$ passivation layer (Figure 2).

Fischer-Tropsch Synthesis. The cobalt-weight-based activity (cobalt time yield, CTY) of the $\mathrm{TiO}_{2}$-supported samples was evaluated over $100 \mathrm{~h}$ on stream (Figure $3 \mathrm{~b}$, Table 2). $\mathrm{Co} 6 / \mathrm{TiO}_{2}$ was the most active after $100 \mathrm{~h}$ followed by $\mathrm{Co} 12 / \mathrm{TiO}_{2}$, which was initially more active but deactivated faster. $\mathrm{Co} 3 / \mathrm{TiO}_{2}$ was a factor 5 less active per unit weight of cobalt over the entire time range studied. Interestingly, the 6 and $12 \mathrm{~nm}$ Co-NC catalysts were similar or even higher in CTY than the IWI-Co/ $\mathrm{TiO}_{2}$ catalyst, indicating that these Co$\mathrm{NC}$ were adequately activated and that relevant catalytic results were obtained with these NC-based model systems. 

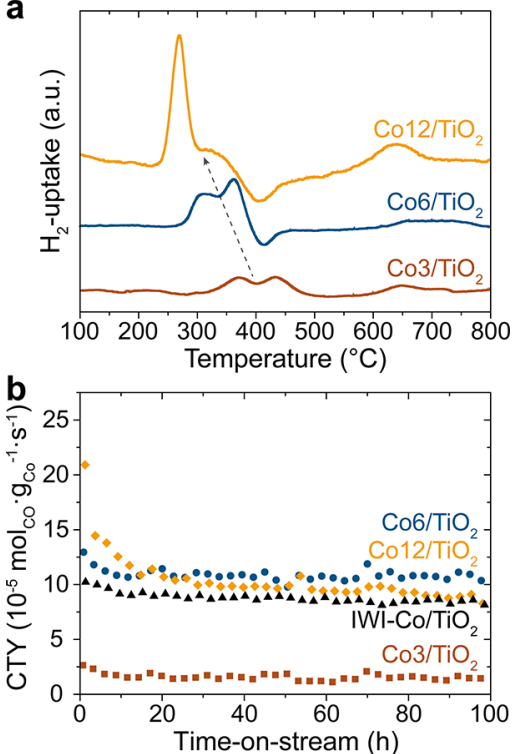

Figure 3. Reduction and catalytic activity of the $\mathrm{TiO}_{2}$-supported samples. (a) Reduction profiles obtained by TPR normalized to the mass of sample and (b) catalytic activity (CTY) in FT as a function of time-on-stream at $20 \mathrm{bar}, 220^{\circ} \mathrm{C}, 2 \mathrm{H}_{2} / \mathrm{CO}(\mathrm{v} / \mathrm{v})$, GHSV $=1950-$ $5900 \mathrm{~h}^{-1}$, and $X_{\mathrm{CO}}=5-60 \%$.

Furthermore, the selectivity toward $\mathrm{C}_{5+}$ products was around $85 \%$ for all $\mathrm{TiO}_{2}$-supported samples, except for $\mathrm{Co} 3 / \mathrm{TiO}_{2}$ whose $\mathrm{C}_{5+}$-selectivity was only $57 \%$ (Table 2 ).

The catalytic activity of the $\mathrm{Co} / \mathrm{SiO}_{2}$ samples was investigated over $100 \mathrm{~h}$ on stream at $\mathrm{CO}$ conversion levels between 15 and 30\% (Figure S6, Table 2). The cobalt-weightbased activities of $\mathrm{Co6} / \mathrm{SiO}_{2}$ and $\mathrm{Co} 9 / \mathrm{SiO}_{2}$ were the highest of all investigated catalysts. The $3 \mathrm{~nm}$ Co-NC displayed again the lowest activity of the series, yet $\mathrm{Co} 3 / \mathrm{SiO}_{2}$ was a factor 6 more active per unit weight of cobalt than $\mathrm{Co} 3 / \mathrm{TiO}_{2}$. The $\mathrm{C}_{5+}{ }^{-}$ selectivities of the $\mathrm{SiO}_{2}$-supported catalysts varied between 76 and $79 \%$ and were overall lower than that of most $\mathrm{TiO}_{2}$ supported catalysts $(\sim 85 \%)$. This observation corresponds well with earlier findings of $\mathrm{TiO}_{2}$ promoting the $\mathrm{C}_{5+}$-selectivity of cobalt catalysts in FT. ${ }^{49}$

The deactivation and observed differences in activity could be caused by several mechanisms, such as carbon deposition, ${ }^{50}$ metal-support compound formation, ${ }^{51}$ or net particle growth. ${ }^{51}$ To investigate the occurrence of particle growth in more detail, the spent catalysts were analyzed with TEM (Table 2, Figure 4, Figure S7). All Co-NC supported on $\mathrm{TiO}_{2}$, as well as the IWI-Co/ $\mathrm{TiO}_{2}$, had grown to $\sim 13 \mathrm{~nm}$ on average,
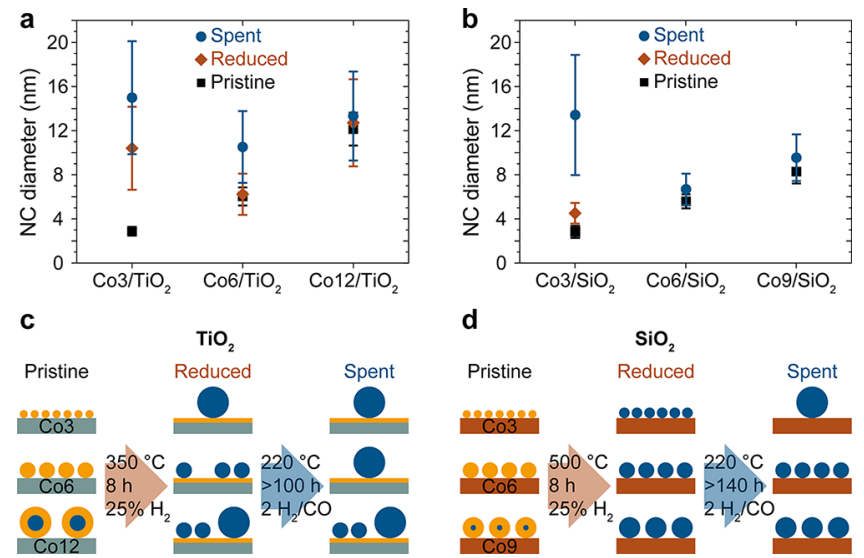

Figure 4. Average cobalt particle sizes of the samples in the pristine, reduced, and spent state. $(\mathrm{a}, \mathrm{b})$ Average Co-NC sizes from TEM analysis of the $\mathrm{TiO}_{2}$ - and $\mathrm{SiO}_{2}$-supported samples, respectively. The bars give the standard deviation of the average particle size. Schematic illustration of the sintering behavior of the different sizes on (c) $\mathrm{TiO}_{2}$ and on (d) $\mathrm{SiO}_{2}$ after different treatments. In these illustrations, $\mathrm{Co}^{2+}$ or $\mathrm{Co}^{3+}$ is depicted in yellow, and $\mathrm{Co}^{0}$ is depicted in blue. Migration of $\mathrm{Co}$ to $\mathrm{TiO}_{2}$ during reduction was observed by EDX.

which was in line with recently reported particle sizes of a Co$\mathrm{Re} / \mathrm{TiO}_{2}$ catalyst after various periods on stream. ${ }^{51} \mathrm{On} \mathrm{SiO}_{2}$, the initially $3 \mathrm{~nm}$ Co-NC had also sintered to $13 \mathrm{~nm}$, while the 6 and $9 \mathrm{~nm} \mathrm{Co-NC}$ were stable.

Using the particle sizes of the spent catalysts and the activities at 90-100 $\mathrm{h}$ on stream, the surface-specific activities (turnover frequencies, TOF) were calculated (Table 2). The TOF of all $\mathrm{TiO}_{2}$-supported catalysts except $\mathrm{Co} 3 / \mathrm{TiO}_{2}$ was around $65 \times 10^{-3} \mathrm{~s}^{-1}$, in line with previous reports. ${ }^{52-54}$ The identical TOF of 6 and $12 \mathrm{~nm}$ Co-NC on $\mathrm{TiO}_{2}$ and the IWI$\mathrm{Co} / \mathrm{TiO}_{2}$ catalyst showed that the active cobalt sites were not affected by the presence of residual ligands or other factors specific to the NC-based synthesis method. The apparent TOF of $\mathrm{Co} 3 / \mathrm{TiO}_{2}$, based on the particle size of the catalyst and the end-of-run activity, was only $12 \times 10^{-3} \mathrm{~s}^{-1}$ (Table 2). This was remarkable, because the Co particles in $\mathrm{Co} 3 / \mathrm{TiO}_{2}$ had grown outside of the size regime where particle size effects typically cause low activities $(<6-8 \mathrm{~nm}) .^{14,15,22}$ Therefore, a TOF similar to the others $\left(65 \times 10^{-3} \mathrm{~s}^{-1}\right)$ should have been obtained. Instead, the low apparent TOF was ascribed to loss of cobalt from the metal particles to the $\mathrm{TiO}_{2}$ resulting in less metallic surface area available for catalysis. Judging from the decrease in TOF, up to $80 \%$ of the cobalt was lost in this manner.

Table 2. Catalytic Performance at $20 \mathrm{bar}, 220^{\circ} \mathrm{C}$, and $2 \mathrm{H}_{2} / \mathrm{CO}(\mathrm{v} / \mathrm{v})^{b}$

\begin{tabular}{|c|c|c|c|c|c|c|c|c|}
\hline sample & GHSV $\left(h^{-1}\right)$ & $X_{\mathrm{CO}}(\%)$ & $\mathrm{CTY}^{a}$ & TOF $\left(10^{-3} \mathrm{~s}^{-1}\right)$ & $S_{\mathrm{Cl}}\left(\%_{\mathrm{C}}\right)$ & $S_{\mathrm{C} 2-\mathrm{C} 4}\left(\%_{\mathrm{C}}\right)$ & $S_{\mathrm{C} 5+}\left(\%_{\mathrm{C}}\right)$ & $\mathrm{D}[3,2]_{\text {spent }}(\mathrm{nm})$ \\
\hline $\mathrm{Co} 3 / \mathrm{TiO}_{2}$ & 2000 & 4.6 & 1.4 & 12 & 21 & 21 & 57 & $15 \pm 5.1$ \\
\hline $\mathrm{Co} 6 / \mathrm{TiO}_{2}$ & 3100 & 23 & 11 & 66 & 9.2 & 8.1 & 83 & $11 \pm 3.3$ \\
\hline $\mathrm{Co} 12 / \mathrm{TiO}_{2}$ & 6900 & 24 & 8.6 & 68 & 8.2 & 5.9 & 86 & $13 \pm 4.0$ \\
\hline IWI-Co/ $\mathrm{TiO}_{2}$ & 7500 & 18 & 8.4 & 68 & 8.7 & 7.0 & 84 & $14 \pm 5.9$ \\
\hline $\mathrm{Co} 3 / \mathrm{SiO}_{2}$ & 1500 & 25 & 8.5 & 67 & 13 & 12 & 76 & $13 \pm 5.5$ \\
\hline $\mathrm{Co} 6 / \mathrm{SiO}_{2}$ & 5500 & 16 & 21 & 82 & 14 & 11 & 76 & $6.7 \pm 1.4$ \\
\hline $\mathrm{Co} 9 / \mathrm{SiO}_{2}$ & 10800 & 21 & 19 & 106 & 13 & 8.7 & 79 & $9.6 \pm 2.1$ \\
\hline
\end{tabular}

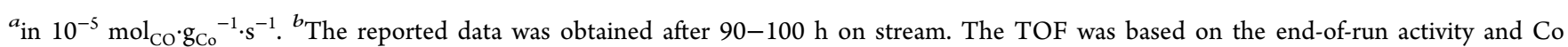
particle size $(\mathrm{D}[3,2])$ of the spent samples. The Sauter mean diameter ( \pm standard deviation) of the Co-NC was analyzed in the spent and passivated state and corrected for the lattice expansion due to the $3 \mathrm{~nm} \mathrm{CoO}$ passivation layer. 
The TOF of the $\mathrm{SiO}_{2}$-supported catalysts increased with initial particle size (Table 2 ). In the case of the initially $3 \mathrm{~nm}$ Co-NC on $\mathrm{SiO}_{2}$, the TOF was $67 \times 10^{-3} \mathrm{~s}^{-1}$, which was similar to most $\mathrm{Co} / \mathrm{TiO}_{2}$ catalysts and already somewhat higher than previously reported for $\mathrm{Co} / \mathrm{SiO}_{2}$ catalysts. ${ }^{55}$ However, the intrinsic activities of 6 and $9 \mathrm{~nm} \mathrm{Co-NC}$ on $\mathrm{SiO}_{2}$ were exceptionally high in comparison to the literature. A possible explanation for the different TOF of Co-NC and conventional catalysts could be that the Co-NC approach led to cobalt particles with a higher fraction of $h c p \mathrm{Co}$, which is more active in FT than $f c c$ Co. ${ }^{16-18,56}$ Alternatively, the CoNC could have less interaction with the support, because the Co-NC were formed prior to attachment to the support. For example, when comparing the TEM results of spent $\mathrm{Co} / \mathrm{SiO}_{2}$, the grown particles of $\mathrm{Co} 3 / \mathrm{SiO}_{2}$ were mainly confined between primary $\mathrm{SiO}_{2}$ particles where the contact area with the support was maximal (Figure S7). The Co-NC in Co6/ $\mathrm{SiO}_{2}$ and $\mathrm{Co} 9 / \mathrm{SiO}_{2}$, on the other hand, were still distributed uniformly over the support, and as such, a higher fraction of the cobalt surface area would be accessible to reactants.

Overall, the employed NC-based approach to catalyst synthesis yielded well-defined model systems with reasonable control over the initial NC size and relevant catalytic performance. It is therefore anticipated that these model catalysts are suitable to investigate structure-performance relationships, and already some interesting phenomena were observed here, especially on the growth of NC of specific sizes under reaction conditions. These observations will be investigated and discussed in more detail in the next section.

Sintering of Cobalt Nanocrystals. To investigate the growth of Co-NC, the particle sizes were analyzed using TEM after reduction as well as after catalysis (Figure 4). The $3 \mathrm{~nm}$ Co-NC on $\mathrm{TiO}_{2}$ sintered to particles of $10 \mathrm{~nm}$ already during reduction and grew further to $15 \mathrm{~nm}$ during FT. The $3 \mathrm{~nm} \mathrm{Co-}$ $\mathrm{NC}$ on $\mathrm{SiO}_{2}$ ultimately grew to the same extent, but in this case the particles predominantly sintered during FT. The reduction barely affected the particle size of $\mathrm{Co} 3 / \mathrm{SiO}_{2}$ even though the reduction was performed at $500{ }^{\circ} \mathrm{C}$.

EDX maps of the reduced and passivated $\mathrm{TiO}_{2}$-supported catalysts and $\mathrm{Co} 3 / \mathrm{SiO}_{2}$ were quantified to investigate the location of Co on the supports (Table 3, see Figure S8 for

Table 3. Quantification of the Cobalt Present in the Support and in Particles after Reduction of $\mathrm{Co} / \mathrm{TiO}_{2}$ and $\mathrm{Co} 3 / \mathrm{SiO}_{2}{ }^{a}$

\begin{tabular}{|c|c|c|c|c|c|}
\hline sample & $\begin{array}{l}\mathrm{Co}_{\text {total }} \\
(\mathrm{wt} \%)\end{array}$ & $\begin{array}{c}\text { Co }{ }_{\text {particles }} \\
\text { (wt \%) }\end{array}$ & $\begin{array}{l}\mathrm{Co}_{\text {support }} \\
(\text { wt \%) }\end{array}$ & $\underset{\mathrm{Co}_{\text {particles }} /}{\mathrm{Co}_{\text {total }}}$ & $\begin{array}{c}\mathrm{Co}_{\text {support }} / \\
\mathrm{Co}_{\text {total }}\end{array}$ \\
\hline $\begin{array}{l}\mathrm{Co} 3 / \\
\mathrm{TiO}_{2}\end{array}$ & 3.3 & 1.3 & 2.0 & 0.38 & 0.62 \\
\hline$\frac{\mathrm{Co} 6 /}{\mathrm{TiO}_{2}}$ & 6.8 & 4.1 & 2.7 & 0.61 & 0.39 \\
\hline $\begin{array}{c}\mathrm{Co} 12 / \\
\mathrm{TiO}_{2}\end{array}$ & 11 & 9.2 & 2.2 & 0.81 & 0.19 \\
\hline Co3/ & 2.4 & 2.0 & 0.4 & 0.84 & 0.16 \\
\hline
\end{tabular}

${ }^{a_{T}}$ The total Co loading and the fractions of Co in particles and Co in the support were derived from HAADF-STEM-EDX (Figure S8).

results and experimental details). Compared to ICP (Table 1), the total cobalt loading from EDX was $30-50 \%$ higher on $\mathrm{TiO}_{2}$ and $50 \%$ lower on $\mathrm{SiO}_{2}$. Therefore, relative differences for one and the same sample were considered more representative than the absolute values.
For the reduced and passivated $\mathrm{Co} / \mathrm{TiO}_{2}$ samples, $\sim 2.5 \mathrm{wt}$ $\%$ of Co was found dispersed in the support and not in particles, regardless of NC size and loading. In the case of $\mathrm{Co} 3 / \mathrm{TiO}_{2}$, this amounted to approximately $60 \%$ of the total cobalt content from EDX and might be partially responsible for its low CTY. Furthermore, the Co signal in the EDX maps occasionally followed the contours of $\mathrm{TiO}_{2}$ particles with increased intensity at the surface (Figure S8). This means that a higher Co concentration existed at the surface than in the bulk of the $\mathrm{TiO}_{2}$ particles. In contrast, only $16 \%$ of the Co was found on the silica support for $\mathrm{Co} 3 / \mathrm{SiO}_{2}$, and the remaining $84 \%$ was still present in Co particles. Consequently, no contours of the support were observed in the Co signal from EDX at locations without any particles (Figure S8). These EDX results show that, during reduction, cobalt migrated to the support more with $\mathrm{TiO}_{2}$ than with $\mathrm{SiO}_{2}$, as illustrated in Figure $4 c$,d. These cobalt species on the support were not detected in XRD (Figure S9), probably because of their low concentration and/or low crystallinity. Additionally, the amount of cobalt on the support was assumed to remain constant during FT, because the $\mathrm{Co} / \mathrm{TiO}_{2}$ catalysts did not activate, which would be expected if the cobalt species on the support were reduced under reaction conditions (Figure $3 b$ ).

Small particles have a higher thermodynamic potential ${ }^{57}$ and are therefore more prone to sintering. ${ }^{58,59}$ Interestingly, in these earlier studies, growth took place via monomers that were created upon exposure to $\mathrm{CO}$ under reaction conditions. For example, in the case of $\mathrm{Co} / \mathrm{Al}_{2} \mathrm{O}_{3}$, cobalt subcarbonyls were proposed as monomers that migrate over the support and give rise to particle growth via Ostwald ripening. ${ }^{60-62}$ However, in our $\mathrm{Co} 3 / \mathrm{TiO}_{2}$ sample, a large part of the growth took place already during reduction, so sintering was not induced by $\mathrm{CO}$. When combining these results with the tendency of $60 \%$ of the cobalt in the NC to "leach" to the surface of the $\mathrm{TiO}_{2}$, we propose that different mobile species, possibly cobalt titanates, ${ }^{63}$ spread out over the support and cause a few particles to grow large. This hypothesis is in line with thermodynamic calculations (Figure S10), which showed that it is thermodynamically possible to form small amounts of cobalt titanates under reduction conditions, and agrees with previous observations. ${ }^{64-66}$ Notably, Cats et al. ${ }^{64}$ observed a thin layer of Co species surrounding $\mathrm{TiO}_{2}$ particles, albeit in spent and not in reduced catalysts.

$\mathrm{On} \mathrm{SiO}_{2}$, the formation of cobalt silicates during reduction is thermodynamically limited (Figure S10), and the growth of 3 nm Co-NC occurred mainly during FT. The sintering might therefore be ascribed to $\mathrm{CO}$-induced Ostwald ripening as observed before by Kistamurthy et al. ${ }^{67}$ or particle migration and coalescence. Furthermore, $8 \mathrm{~h}$ plasma cleaning of the pristine samples to remove ligands reduced the particle growth for $\mathrm{Co} 3 / \mathrm{SiO}_{2}$ but not for $\mathrm{Co} 3 / \mathrm{TiO}_{2}$ (Figure S11). This further confirmed that the mechanism responsible for particle growth is different on both supports even though the final particle size is similar.

The $6 \mathrm{~nm}$ Co-NC on $\mathrm{TiO}_{2}$ did not grow during reduction (Figure 4). The driving force for sintering during reduction was thus less than for $\mathrm{Co} 3 / \mathrm{TiO}_{2}$ because of the larger particle size. However, the $\mathrm{NC}$ on $\mathrm{TiO}_{2}$ did grow to $11 \mathrm{~nm}$ during FT. Growth of the $6 \mathrm{~nm}$ Co-NC was not observed on $\mathrm{SiO}_{2}$ even after catalysis, showing that the Co-NC are less stable on $\mathrm{TiO}_{2}$ compared to $\mathrm{SiO}_{2}$. Interestingly, $\mathrm{Co} 6 / \mathrm{TiO}_{2}$ had sintered less than IWI-Co/ $/ \mathrm{TiO}_{2}$ after FT, with final particles sizes of 11 and $14 \mathrm{~nm}$, respectively (Figure S12). Because the average particle 
sizes of both samples were initially comparable while the polydispersity of IWI-Co/ $\mathrm{TiO}_{2}$ was higher, this shows the impact of the width of the particle size distribution on the stability of the cobalt nanoparticles. ${ }^{68-70}$ It nicely illustrates the advantage of the NC-based approach over the traditional synthesis techniques to arrive at more stable catalysts.

On average, $12 \mathrm{~nm}$ Co-NC on $\mathrm{TiO}_{2}$ did not grow, but the particle size distribution did become broader already after reduction (Figure 4). Both smaller and larger particles were thus formed, which implied Ostwald ripening or redispersion of cobalt, possibly via cobalt-ion migration, under reducing conditions. No evidence of Co-NC growth or redispersion was apparent on $\mathrm{Co} 9 / \mathrm{SiO}_{2}$ indicating that Co mobility was more extensive with the $\mathrm{TiO}_{2}$ support or the somewhat larger CoNC sizes. Extending the reduction to $16 \mathrm{~h}$ instead of $8 \mathrm{~h}$ did not change the particle size distribution of $\mathrm{Co} 12 / \mathrm{TiO}_{2}$ further (Figure S13). This observation is qualitatively in line with the results of Xaba et al. ${ }^{71}$ on titania P25, although their Co particles were substantially larger $(\sim 50 \mathrm{~nm})$.

The size evolution of individual Co-NC in $\mathrm{Co} 12 / \mathrm{TiO}_{2}$ was followed before and after reduction and passivation to investigate the redispersion in more detail (Figure 5). No
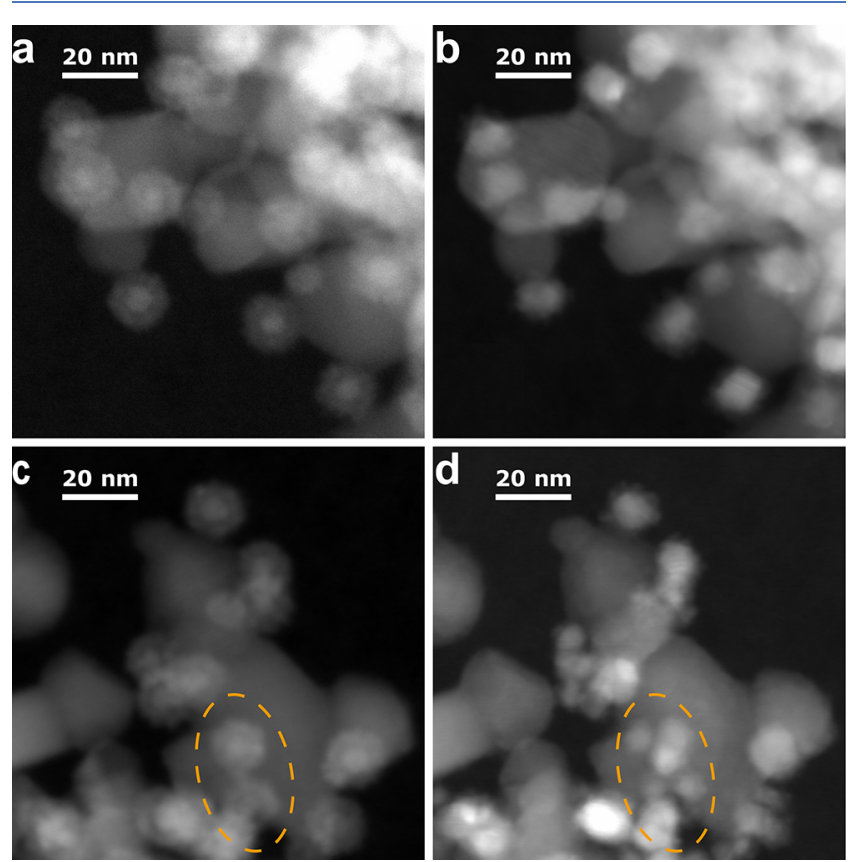

Figure 5. Size evolution of individual $\mathrm{Co}-\mathrm{NC}$ in $\mathrm{Co} 12 / \mathrm{TiO}_{2}$ during reduction. (a,c) HAADF-STEM images of pristine $\mathrm{Co} 12 / \mathrm{TiO}_{2}$ and $(\mathrm{b}, \mathrm{d})$ HAADF-STEM images of the same locations after reduction at $350{ }^{\circ} \mathrm{C}$ for $8 \mathrm{~h}$. The highlighted area contains two particles that disintegrated during reduction and formed multiple smaller particles.

particles were found that had moved from their original position, indicating low mobility of the Co-NC as a whole and making migration and coalescence unlikely as a pathway for particle growth during reduction. Furthermore, approximately $5 \%$ of the particles broke up into multiple smaller particles (Figure 5c,d highlighted area, Figure S14). This redispersion caused an increase in the fraction of 5-8 $\mathrm{nm}$ particles, resulting in broadening of the particle size distribution.

Two reasons can be proposed for the disintegration of the NC. First, it might be favorable for certain particles to maximize their contact area with the support, since the interaction between metals and reducible supports such as $\mathrm{TiO}_{2}$ can lead to dynamic systems under reducing conditions. ${ }^{44}$ Second, the core-shell structure in pristine Co12/ $\mathrm{TiO}_{2}$ could be an intermediate stage of the Kirkendall effect. ${ }^{11}$ Sasdavian et al. ${ }^{45}$ investigated this effect for Co-NC of different sizes on $\mathrm{SiO}_{2}$ and reported similar core-shell particles in the case of incomplete oxidation of $29 \mathrm{~nm}$ particles. Completely oxidized, hollow cobalt oxide particles of $29 \mathrm{~nm}$ disintegrated into multiple smaller particles upon reduction, whereas smaller hollow particles returned to their original size of $11 \mathrm{~nm}$. Based on these results, our $12 \mathrm{~nm}$ Co-NC, being similar in size to their $11 \mathrm{~nm}$ particles, are not expected to disintegrate upon reduction.

\section{CONCLUSIONS}

Here, we investigated the preparation of well-defined $\mathrm{TiO}_{2}-$ and $\mathrm{SiO}_{2}$-supported catalysts via colloidal synthesis of Co-NC and evaluated their catalytic performance in the FischerTropsch synthesis. The 3-12 nm Co-NC were synthesized by a hot-injection method, oxidized at low temperature to restrict magnetic interactions and subsequently attached to $\mathrm{TiO}_{2}$ or $\mathrm{SiO}_{2}$. The catalytic activity of most $\mathrm{TiO}_{2}$-supported samples was in line with that of a $\mathrm{Co} / \mathrm{TiO}_{2}$ sample prepared by impregnation of cobalt nitrate, proving that relevant catalytic data was obtained with these model catalysts. The cobaltweight-based activity of $3 \mathrm{~nm} \mathrm{Co-NC}$ on $\mathrm{TiO}_{2}$ was 5 -fold lower than expected, and this was partially ascribed to loss of cobalt to the support. Furthermore, the $\mathrm{TiO}_{2}$-supported Co particles and $3 \mathrm{~nm}$ Co-NC on $\mathrm{SiO}_{2}$ sintered, while 6 and $9 \mathrm{~nm}$ Co-NC on $\mathrm{SiO}_{2}$ were stable during reduction and FT. We showed that the interaction between $\mathrm{Co}(\mathrm{O})$ and $\mathrm{TiO}_{2}$ was responsible for the decreased stability of the Co-NC. This study illustrates the promise of synthesizing model catalysts using colloidal techniques, as the high precision in particle size enabled the investigation of effects that have not have been revealed earlier with conventional synthesis techniques.

\section{ASSOCIATED CONTENT}

\section{S Supporting Information}

The Supporting Information is available free of charge on the ACS Publications website at DOI: 10.1021/acscatal.8b03094.

Schematic summary of the catalyst synthesis procedure, additional characterization, and catalytic results (PDF)

\section{AUTHOR INFORMATION}

\section{Corresponding Author}

*E-mail: k.p.dejong@uu.nl.

\section{ORCID}

Tom W. van Deelen: 0000-0002-3666-4576

\section{Notes}

The authors declare no competing financial interest.

\section{ACKNOWLEDGMENTS}

T.W.v.D and K.P.d.J. acknowledge Shell Global Solutions and The Netherlands Association for Scientific Research (NWO) for funding through the CHIPP framework. N.A.K., J.Z., and K.P.d.J. acknowledge the European Research Council, EU FP7 ERC Advanced Grant no. 338846 for funding. We thank Pasi Paalanen and Lennart Weber $\left(\mathrm{N}_{2}\right.$-physisorption), Carlos Hernández Mejía (TPR), and Helen de Waard (ICP-OES) for the measurements indicated. 


\section{REFERENCES}

(1) Zečević, J.; Vanbutsele, G.; de Jong, K. P.; Martens, J. A. Nanoscale Intimacy in Bifunctional Catalysts for Selective Conversion of Hydrocarbons. Nature 2015, 528, 245-248.

(2) Behrens, M.; Studt, F.; Kasatkin, I.; Kühl, S.; Hävecker, M.; Abild-pedersen, F.; Zander, S.; Girgsdies, F.; Kurr, P.; Kniep, B.-L.; Tovar, M.; Fischer, R. W.; Nørskov, J. K.; Schlögl, R. The Active Site of Methanol Synthesis over $\mathrm{Cu} / \mathrm{ZnO} / \mathrm{Al}_{2} \mathrm{O}_{3}$ Industrial Catalysts. Science 2012, 336, 893-898.

(3) Cargnello, M.; Doan-Nguyen, V. V. T.; Gordon, T. R.; Diaz, R. E.; Stach, E. A.; Gorte, R. J.; Fornasiero, P.; Murray, C. B. Control of Metal Nanocrystal Size Reveals Metal-Support Interface Role for Ceria Catalysts. Science 2013, 341, 771-773.

(4) Torres Galvis, H. M.; Bitter, J. H.; Khare, C. B.; Ruitenbeek, M.; Dugulan, A. I.; de Jong, K. P. Supported Iron Nanoparticles as Catalysts for Sustainable Production of Lower Olefins. Science 2012, 335, 835-838.

(5) Zaera, F. Nanostructured Materials for Applications in Heterogeneous Catalysis. Chem. Soc. Rev. 2013, 42, 2746-2762.

(6) Jia, C.-J.; Schüth, F. Colloidal Metal Nanoparticles as a Component of Designed Catalyst. Phys. Chem. Chem. Phys. 2011, 13, 2457-2487.

(7) Munnik, P.; de Jongh, P. E.; de Jong, K. P. Recent Developments in the Synthesis of Supported Catalysts. Chem. Rev. 2015, 115, 66876718.

(8) An, K.; Somorjai, G. A. Size and Shape Control of Metal Nanoparticles for Reaction Selectivity in Catalysis. ChemCatChem 2012, 4, 1512-1524.

(9) Werner, S.; Johnson, G. R.; Bell, A. T. Synthesis and Characterization of Supported Cobalt-Manganese Nanoparticles as Model Catalysts for Fischer-Tropsch Synthesis. Chem CatChem 2014, 6, 2881-2888.

(10) Zacharaki, E.; Beato, P.; Tiruvalam, R. R.; Andersson, K. J.; Fjellvåg, H.; Sjåstad, A. O. From Colloidal Monodisperse Nickel Nanoparticles to Well-Defined $\mathrm{Ni} / \mathrm{Al}_{2} \mathrm{O}_{3}$ Model Catalysts. Langmuir 2017, 33, 9836-9843.

(11) Yin, Y.; Rioux, R. M.; Erdonmez, C. K.; Hughes, S.; Somorjai, G. A.; Alivisatos, A. P. Formation of Hollow Nanocrystals Through the Nanoscale Kirkendall Effect. Science 2004, 304, 711-714.

(12) van Deelen, T. W.; Su, H.; Sommerdijk, N. A. J. M.; de Jong, K. P. Assembly and Activation of Supported Cobalt Nanocrystal Catalysts for the Fischer-Tropsch Synthesis. Chem. Commun. 2018, 54, 2530-2533.

(13) Zhong, L.; Yu, F.; An, Y.; Zhao, Y.; Sun, Y.; Li, Z.; Lin, T.; Lin, Y.; Qi, X.; Dai, Y.; Gu, L.; Hu, J.; Jin, S.; Shen, Q.; Wang, H. Cobalt Carbide Nanoprisms for Direct Production of Lower Olefins from Syngas. Nature 2016, 538, 84-87.

(14) Bezemer, G. L.; Bitter, J. H.; Kuipers, H. P. C. E.; Oosterbeek, H.; Holewijn, J. E.; Xu, X.; Kapteijn, F.; van Dillen, A. J.; de Jong, K. P. Cobalt Particle Size Effects in the Fischer-Tropsch Reaction Studied with Carbon Nanofiber Supported Catalysts. J. Am. Chem. Soc. 2006, 128, 3956-3964.

(15) den Breejen, J. P.; Radstake, P. B.; Bezemer, G. L.; Bitter, J. H.; Frøseth, V.; Holmen, A.; de Jong, K. P. On the Origin of the Cobalt Particle Size Effects in Fischer-Tropsch Catalysis. J. Am. Chem. Soc. 2009, 131, 7197-7203.

(16) Sadeqzadeh, M.; Karaca, H.; Safonova, O. V.; Fongarland, P.; Chambrey, S.; Roussel, P.; Griboval-Constant, A.; Lacroix, M.; Curulla-Ferré, D.; Luck, F.; Khodakov, A. Y. Identification of the Active Species in the Working Alumina-Supported Cobalt Catalyst under Various Conditions of Fischer-Tropsch Synthesis. Catal. Today 2011, 164, 62-67.

(17) Liu, J.-X.; Su, H.-Y.; Sun, D.-P.; Zhang, B.-Y.; Li, W.-X. Crystallographic Dependence of CO Activation on Cobalt Catalysts: HCP versus FCC. J. Am. Chem. Soc. 2013, 135, 16284-16287.

(18) Lyu, S.; Wang, L.; Zhang, J.; Liu, C.; Sun, J.; Peng, B.; Wang, Y.; Rappé, K. G.; Zhang, Y.; Li, J.; Nie, L. Role of Active Phase in Fischer-Tropsch Synthesis: Experimental Evidence of CO Activation over Single-Phase Cobalt Catalysts. ACS Catal. 2018, 8, 7787-7798.
(19) Gual, A.; Godard, C.; Castillón, S.; Curulla-Ferré, D.; Claver, C. Colloidal $\mathrm{Ru}, \mathrm{Co}$ and Fe-Nanoparticles. Synthesis and Application as Nanocatalysts in the Fischer-Tropsch Process. Catal. Today 2012, 183, 154-171.

(20) Wang, H.; Zhou, W.; Liu, J.-X.; Si, R.; Sun, G.; Zhong, M.-Q.; Su, H.-Y.; Zhao, H.-B.; Rodriguez, J. A.; Pennycook, S. J.; Idrobo, J.C.; Li, W.-X.; Kou, Y.; Ma, D. Platinum-Modulated Cobalt Nanocatalysts for Low-Temperature Aqueous-Phase FischerTropsch Synthesis. J. Am. Chem. Soc. 2013, 135, 4149-4158.

(21) Delgado, J. A.; Claver, C.; Castillón, S.; Curulla-Ferré, D.; Godard, C. Correlation between Hydrocarbon Product Distribution and Solvent Composition in the Fischer-Tropsch Synthesis Catalyzed by Colloidal Cobalt Nanoparticles. ACS Catal. 2015, 5, $4568-4578$.

(22) Prieto, G.; Martínez, A.; Concepción, P.; Moreno-Tost, R. Cobalt Particle Size Effects in Fischer-Tropsch Synthesis: Structural and in Situ Spectroscopic Characterisation on Reverse MicelleSynthesised Co/ITQ-2 Model Catalysts. J. Catal. 2009, 266, 129144.

(23) Fischer, N.; van Steen, E.; Claeys, M. Structure Sensitivity of the Fischer-Tropsch Activity and Selectivity on Alumina Supported Cobalt Catalysts. J. Catal. 2013, 299, 67-80.

(24) Lögdberg, S.; Boutonnet, M.; Walmsley, J. C.; Järås, S.; Holmen, A.; Blekkan, E. A. Effect of Water on the Space-Time Yield of Different Supported Cobalt Catalysts during Fischer-Tropsch Synthesis. Appl. Catal., A 2011, 393, 109-121.

(25) Ralston, W. T.; Melaet, G.; Saephan, T.; Somorjai, G. A. Evidence of Structure Sensitivity in the Fischer-Tropsch Reaction on Model Cobalt Nanoparticles by Time-Resolved Chemical Transient Kinetics. Angew. Chem., Int. Ed. 2017, 56, 7415-7419.

(26) Melaet, G.; Lindeman, A. E.; Somorjai, G. A. Cobalt Particle Size Effects in the Fischer-Tropsch Synthesis and in the Hydrogenation of $\mathrm{CO}_{2}$ Studied with Nanoparticle Model Catalysts on Silica. Top. Catal. 2014, 57, 500-507.

(27) Herranz, T.; Deng, X.; Cabot, A.; Guo, J.; Salmeron, M. Influence of the Cobalt Particle Size in the CO Hydrogenation Reaction Studied by In Situ X-Ray Absorption Spectroscopy. J. Phys. Chem. B 2009, 113, 10721-10727.

(28) Lee, Y.-J.; Park, J.-Y.; Jun, K.-W.; Wook Bae, J.; Prasad, P. S. S. Controlled Nanocrystal Deposition for Higher Degree of Reduction in $\mathrm{Co} / \mathrm{Al}_{2} \mathrm{O}_{3}$ Catalyst. Catal. Lett. 2009, 130, 198-203.

(29) Park, J.-Y.; Lee, Y.-J.; Karandikar, P. R.; Jun, K.-W.; Ha, K.-S.; Park, H.-G. Fischer-Tropsch Catalysts Deposited with SizeControlled $\mathrm{Co}_{3} \mathrm{O}_{4}$ Nanocrystals: Effect of Co Particle Size on Catalytic Activity and Stability. Appl. Catal., A 2012, 411-412, 1523.

(30) Oukaci, R.; Singleton, A. H.; Goodwin, J. G. Comparison of Patented Co F-T Catalysts Using Fixed-Bed and Slurry Bubble Column Reactors. Appl. Catal., A 1999, 186, 129-144.

(31) Morales, F.; de Smit, E.; de Groot, F. M. F.; Visser, T.; Weckhuysen, B. M. Effects of Manganese Oxide Promoter on the CO and $\mathrm{H}_{2}$ Adsorption Properties of Titania-Supported Cobalt FischerTropsch Catalysts. J. Catal. 2007, 246, 91-99.

(32) Tauster, S. J.; Fung, S. C.; Garten, R. L. Strong Metal-Support Interactions. Group 8 Noble Metals Supported on $\mathrm{TiO}_{2}$. J. Am. Chem. Soc. 1978, 100, 170-175.

(33) Tauster, S. J.; Fung, S. C.; Baker, R. T.; Horsley, J. A. Strong Interactions in Supported-Metal Catalysts. Science 1981, 211, 11211125.

(34) Eschemann, T. O.; de Jong, K. P. Deactivation Behavior of Co/ $\mathrm{TiO}_{2}$ Catalysts during Fischer-Tropsch Synthesis. ACS Catal. 2015, 5, 3181-3188.

(35) Hong, J.; Du, J.; Wang, B.; Zhang, Y.; Liu, C.; Xiong, H.; Sun, F.; Chen, S.; Li, J. Plasma-Assisted Preparation of Highly Dispersed Cobalt Catalysts for Enhanced Fischer-Tropsch Synthesis Performance. ACS Catal. 2018, 8, 6177-6185.

(36) Delgado, J. A.; Claver, C.; Castillón, S.; Curulla-Ferré, D.; Ordomsky, V. V.; Godard, C. Fischer-Tropsch Synthesis Catalysed 
by Small $\mathrm{TiO}_{2}$ Supported Cobalt Nanoparticles Prepared by Sodium Borohydride Reduction. Appl. Catal., A 2016, 513, 39-46.

(37) Delgado, J. A.; Claver, C.; Castillón, S.; Curulla-Ferré, D.; Ordomsky, V. V.; Godard, C. Effect of Polymeric Stabilizers on Fischer-Tropsch Synthesis Catalyzed by Cobalt Nanoparticles Supported on $\mathrm{TiO}_{2}$. J. Mol. Catal. A: Chem. 2016, 417, 43-52.

(38) Melaet, G.; Ralston, W. T.; Li, C.-S.; Alayoglu, S.; An, K.; Musselwhite, N.; Kalkan, B.; Somorjai, G. A. Evidence of Highly Active Cobalt Oxide Catalyst for the Fischer-Tropsch Synthesis and $\mathrm{CO}_{2}$ Hydrogenation. J. Am. Chem. Soc. 2014, 136, 2260-2263.

(39) Iablokov, V.; Beaumont, S. K.; Alayoglu, S.; Pushkarev, V. V.; Specht, C.; Gao, J.; Alivisatos, A. P.; Kruse, N.; Somorjai, G. A. SizeControlled Model Co Nanoparticle Catalysts for $\mathrm{CO}_{2}$ Hydrogenation: Synthesis, Characterization, and Catalytic Reactions. Nano Lett. 2012, 12, 3091-3096.

(40) Casavola, M.; Hermannsdörfer, J.; de Jonge, N.; Dugulan, A. I.; de Jong, K. P. Fabrication of Fischer-Tropsch Catalysts by Deposition of Iron Nanocrystals on Carbon Nanotubes. Adv. Funct. Mater. 2015, 25, 5309-5319.

(41) Reuel, R. C.; Bartholomew, C. H. The Stoichiometries of $\mathrm{H}_{2}$ and CO Adsorptions on Cobalt: Effects of Support and Preparation. J. Catal. 1984, 85, 63-77.

(42) Zacharaki, E.; Kalyva, M.; Fjellvåg, H.; Sjåstad, A. O. Burst Nucleation by Hot Injection for Size Controlled Synthesis of $\varepsilon$-Cobalt Nanoparticles. Chem. Cent. J. 2016, 10, 10.

(43) Wolf, M.; Fischer, N.; Claeys, M. Effectiveness of Catalyst Passivation Techniques Studied in Situ with a Magnetometer. Catal. Today 2016, 275, 135-140.

(44) Hernández Mejía, C.; van Deelen, T. W.; de Jong, K. P. Activity Enhancement of Cobalt Catalysts by Tuning Metal-Support Interactions. Nat. Commun. Accepted.

(45) Sadasivan, S.; Bellabarba, R. M.; Tooze, R. P. Size Dependent Reduction-Oxidation-Reduction Behaviour of Cobalt Oxide Nanocrystals. Nanoscale 2013, 5, 11139-11146.

(46) Wolf, M.; Kotzé, H.; Fischer, N.; Claeys, M. Size Dependent Stability of Cobalt Nanoparticles in High Conversion FischerTropsch Environment. Faraday Discuss. 2017, 197, 243-268.

(47) van Steen, E.; Claeys, M.; Dry, M. E.; van de Loosdrecht, J.; Viljoen, E. L.; Visagie, J. L. Stability of Nanocrystals: Thermodynamic Analysis of Oxidation and Re-Reduction of Cobalt in Water/ Hydrogen Mixtures. J. Phys. Chem. B 2005, 109, 3575-3577.

(48) Tsakoumis, N. E.; Walmsley, J. C.; Rønning, M.; van Beek, W.; Rytter, E.; Holmen, A. Evaluation of Reoxidation Thresholds for $\gamma-$ $\mathrm{Al}_{2} \mathrm{O}_{3}$-Supported Cobalt Catalysts under Fischer-Tropsch Synthesis Conditions. J. Am. Chem. Soc. 2017, 139, 3706-3715.

(49) Prieto, G.; De Mello, M. I. S.; Concepción, P.; Murciano, R.; Pergher, S. B. C.; Martinez, A. Cobalt-Catalyzed Fischer-Tropsch Synthesis: Chemical Nature of the Oxide Support as a Performance Descriptor. ACS Catal. 2015, 5, 3323-3335.

(50) Yang, J.; Tveten, E. Z.; Chen, D.; Holmen, A. Understanding the Effect of Cobalt Particle Size on Fischer-Tropsch Synthesis: Surface Species and Mechanistic Studies by SSITKA and Kinetic Isotope Effect. Langmuir 2010, 26, 16558-16567.

(51) Kliewer, C. E.; Soled, S. L.; Kiss, G. Morphological Transformations during Fischer-Tropsch Synthesis on a TitaniaSupported Cobalt Catalyst. Catal. Today 2018, DOI: 10.1016/ j.cattod.2018.05.021.

(52) Iglesia, E.; Soled, S. L.; Fiato, R. A. Fischer-Tropsch Synthesis on Cobalt and Ruthenium. Metal Dispersion and Support Effects on Reaction Rate and Selectivity. J. Catal. 1992, 137, 212-224.

(53) Iglesia, E. Design, Synthesis, and Use of Cobalt-Based FischerTropsch Synthesis Catalysts. Appl. Catal., A 1997, 161, 59-78.

(54) Storsæter, S.; Borg, Ø.; Blekkan, E. A.; Holmen, A. Study of the Effect of Water on Fischer-Tropsch Synthesis over Supported Cobalt Catalysts. J. Catal. 2005, 231, 405-419.

(55) Munnik, P.; de Jongh, P. E.; de Jong, K. P. Control and Impact of the Nanoscale Distribution of Supported Cobalt Particles Used in Fischer-Tropsch Catalysis. J. Am. Chem. Soc. 2014, 136, 7333-7340.
(56) Eschemann, T. O.; Lamme, W. S.; Manchester, R. L.; Parmentier, T. E.; Cognigni, A.; Rønning, M.; de Jong, K. P. Effect of Support Surface Treatment on the Synthesis, Structure, and Performance of Co/CNT Fischer-Tropsch Catalysts. J. Catal. 2015, $328,130-138$.

(57) Campbell, C. T.; Mao, Z. Chemical Potential of Metal Atoms in Supported Nanoparticles: Dependence upon Particle Size and Support. ACS Catal. 2017, 7, 8460-8466.

(58) Munnik, P.; Velthoen, M. E. Z.; de Jongh, P. E.; De Jong, K. P.; Gommes, C. J. Nanoparticle Growth in Supported Nickel Catalysts during Methanation Reaction-Larger Is Better. Angew. Chem., Int. Ed. 2014, 53, 9493-9497.

(59) Ouyang, R.; Liu, J.-X.; Li, W.-X. Atomistic Theory of Ostwald Ripening and Disintegration of Supported Metal Particles under Reaction Conditions. J. Am. Chem. Soc. 2013, 135, 1760-1771.

(60) Wilson, J.; de Groot, C. P. M. Atomic-Scale Restructuring in High-Pressure Catalysis. J. Phys. Chem. 1995, 99, 7860-7866.

(61) Claeys, M.; Dry, M. E.; van Steen, E.; van Berge, P. J.; Booyens, S.; Crous, R.; Van Helden, P.; Labuschagne, J.; Moodley, D. J.; Saib, A. M. Impact of Process Conditions on the Sintering Behavior of an Alumina-Supported Cobalt Fischer-Tropsch Catalyst Studied with an in Situ Magnetometer. ACS Catal. 2015, 5, 841-852.

(62) Janse van Rensburg, W.; van Helden, P.; Moodley, D. J.; Claeys, M.; Petersen, M. A.; van Steen, E. Role of Transient Co-Subcarbonyls in Ostwald Ripening Sintering of Cobalt Supported on $\gamma$-Alumina Surfaces. J. Phys. Chem. C 2017, 121, 16739-16753.

(63) Jongsomjit, B.; Sakdamnuson, C.; Goodwin, J. G.; Praserthdam, P. Co-Support Compound Formation in Titania-Supported Cobalt Catalyst. Catal. Lett. 2004, 94, 209-215.

(64) Cats, K. H.; Andrews, J. C.; Stéphan, O.; March, K.; Karunakaran, C.; Meirer, F.; de Groot, F. M. F.; Weckhuysen, B. M. Active Phase Distribution Changes within a Catalyst Particle during Fischer-Tropsch Synthesis as Revealed by Multi-Scale Microscopy. Catal. Sci. Technol. 2016, 6, 4438-4449.

(65) Riva, R.; Miessner, H.; Vitali, R.; Del Piero, G. Metal-support Interaction in $\mathrm{Co} / \mathrm{SiO}_{2}$ and $\mathrm{Co} / \mathrm{TiO}_{2}$. Appl. Catal., A 2000, 196, 111-123.

(66) Wang, C.-B.; Cai, Y.; Wachs, I. E. Reaction-Induced Spreading of Metal Oxides onto Surfaces of Oxide Supports during Alcohol Oxidation: Phenomenon, Nature, and Mechanisms. Langmuir 1999, $15,1223-1235$.

(67) Kistamurthy, D.; Saib, A. M.; Moodley, D. J.; Niemantsverdriet, J. W.; Weststrate, C. J. Ostwald Ripening on a Planar $\mathrm{Co} / \mathrm{SiO}_{2}$ Catalyst Exposed to Model Fischer-Tropsch Synthesis Conditions. J. Catal. 2015, 328, 123-129.

(68) Hu, S.; Li, W.-X. Influence of Particle Size Distribution on Life Time and Thermal Stability of Ostwald Ripening of Supported Particles. ChemCatChem 2018, 10, 2900-2907.

(69) Wettergren, K.; Schweinberger, F. F.; Deiana, D.; Ridge, C. J.; Crampton, A. S.; Rötzer, M. D.; Hansen, T. W.; Zhdanov, V. P.; Heiz, U.; Langhammer, C. High Sintering Resistance of Size-Selected Platinum Cluster Catalysts by Suppressed Ostwald Ripening. Nano Lett. 2014, 14, 5803-5809.

(70) Zhang, S.; Cargnello, M.; Cai, W.; Murray, C. B.; Graham, G. W.; Pan, X. Revealing Particle Growth Mechanisms by Combining High-Surface-Area Catalysts Made with Monodisperse Particles and Electron Microscopy Conducted at Atmospheric Pressure. J. Catal. 2016, 337, 240-247.

(71) Xaba, B. M.; de Villiers, J. P. R. Sintering Behaviour of $\mathrm{TiO}_{2-}$ Supported Model Cobalt Fischer-Tropsch Catalysts under $\mathrm{H}_{2}$ Reducing Conditions and Elevated Temperature. Ind. Eng. Chem. Res. 2016, 55, 9397-9407. 